\title{
Rypsirehujen vaikutus maidon rasvahappokoostumukseen
}

\author{
Piia Kairenius ${ }^{1)}$, Vesa Toivonen ${ }^{1)}$, Seppo Ahvenjärvi ${ }^{1)}$, Aila Vanhatalo ${ }^{2)}$ ja Kevin J. Shingfield ${ }^{1)}$ \\ ${ }^{1)}$ MTT, Kotieläintuotannon tutkimus, 31600 Jokioinen, etunimi.sukunimi@mtt.fi \\ ${ }^{2)}$ Kotieläintieteenlaitos, PL 28, 00014 Helsingin yliopisto, etunimi.sukunimi@helsinki.fi
}

\section{Tiivistelmä}

Maitorasvan rasvahappokoostumusta voidaan muuttaa varsin tehokkaasti lehmien ruokintaa muuttamalla. Lisäämällä rehuun kasvirasvaa vähennetään lyhytketjuisten, tyydyttyneiden rasvahappojen (C12:0, C14:0 ja $\mathrm{C} 16: 0)$ pitoisuutta maidossa ja lisätään pitkäketjuisten, kerta (MUFA)- ja monityydyttymättömien (PUFA) rasvahappojen osuutta. Lisättäessä rehuun suuria annoksia rasvaa, esimerkiksi öljynä, rehun monityydyttymättömät rasvahapot pelkistyvät pötsissä epätäydellisesti ja pötsiin kertyy erilaisia reaktiovälituotteita, kuten trans-rasvahappoja. Öljykasvinsiemenien kuoret suojaavat monityydyttymättömiä rasvahappoja pötsimikrobien toiminnalta ja saattavat siten ehkäistä myös trans-rasvahappojen muodostusta pötsissä. Tämän tutkimuksen tavoitteena oli selvittää kuinka hyvin rypsinsiemenen kuori suojaa rypsin monityydyttymättömiä rasvahappoja pelkistykseltä pötsissä ja mikä on kokonaisten öljykasvinsiemenien vaikutus maidon rasvahappokoostumukseen. Koe suoritettiin 4 x 4 latinalaisen neliön koemallin mukaan. Koekäsittelyn mukaan (kontrolli, ei rasvalisää; C) lehmien rehuseokseen sekoitettiin rypsiöljyä (RO), kokonaisia rypsinsiemeniä (WR) tai murskattuja rypsinsiemeniä (MR) siten, että rehuseokset sisälsivät rasvaa noin $50 \mathrm{~g} / \mathrm{kg}$ KA. Rypsirasvojen lisäys ei vaikuttanut merkitsevästi kokonaiskuiva-aineen syöntiin $(19.3,18.8,21.8$ ja $20.5 \mathrm{~kg} / \mathrm{pv}$ koekäsittelyissä $\mathrm{C}, \mathrm{RO}$, WR ja MR vastaavasti), eikä lehmien maitotuotokseen $(28.5,28.0,28.3$ ja $26.9 \mathrm{~kg} / \mathrm{pv})$, valkuais$(31.3,31.0,31.1$ ja $30.5 \mathrm{~g} / \mathrm{kg})$, rasva- $(41.2,42.2,43.0 \mathrm{ja} 43.0 \mathrm{~g} / \mathrm{kg})$ ja laktoosipitoisuuksiin (48.9, $49.0,49.6$ ja $48.6 \mathrm{~g} / \mathrm{kg}$ ). Rypsirasvojen lisäys muutti maitorasvan koostumusta merkitsevästi. Tyydyttyneiden rasvahappojen osuus maidon kokonaisrasvahapoista väheni $(72.1,58.1,65.3$ ja $61.1 \mathrm{~g} / 100 \mathrm{~g}$ rasvahappoja; RA) ja kertatyydyttymättömien lisääntyi $(26.4,39.9,33.2$ ja $37.4 \mathrm{~g} / 100 \mathrm{~g}$ RA) rypsirasvoja lisättäessä. Tyydyttyneiden rasvahappojen osuuden väheneminen johtui erityisesti maitorauhasen de novo-synteesissä muodostuvien lyhytketjuisten rasvahappojen määrän vähentymisestä. Öljyhappopitoisuuden lisääntyminen (18.4, 30.2, 25.5 ja 29.4 g/100g RA) selittää lähes yksinomaan kertatyydyttymättömien rasvahappojen kokonaismäärän lisääntymisen maidon kokonaisrasvapoista. Rypsiöljylisäys nosti merkitsevästi maidon trans-rasvahappojen pitoisuutta muihin rypsirasvoihin verrattuna $(3.91,7.12,4.51$ ja 5.08 g/100g RA). Linolihapon (C18:2n-6) pitoisuus pieneni merkitsevästi $(1.11,0.98,0.98$ ja $0.92 \mathrm{~g} / 100 \mathrm{~g}$ RA). Cis-9, trans-11 CLA (engl. conjugated linoleic acid) oli maidon pääasiallisin CLA-isomeeri ja sen pitoisuus oli suurimmillaan lisättäessä rypsiöljyä lehmien rehuun (351, 597, 285 ja 346 mg/100g RA). Vaikka kaikki rasvalisät vähensivät maitorasvan tyydyttyneiden rasvahappojen pitoisuutta ja lisäsivät MUFA:n ja PUFA:n osuutta kontrolliruokintaan verrattuna, ravitsemuksellisesti paras muutos maidon rasvahappokoostumukseen saatiin lisättäessä lehmien rehuun murskattuja rypsinsiemeniä.

Asiasanat: lypsylehmä, maitorasva, MUFA, PUFA, CLA, trans-rasvahapot, rypsinsiemen, rypsiöljy 


\section{Johdanto}

Maitorasvan koostumus on monipuolinen. Se sisältää yhteensä noin 400 erilaista rasvahappoa, joista suuri osa on lyhyitä ja keskipitkiä rasvahappoja (C4-C14, C16). Pitkäketjuisten, yli 18 hiiliatomia sisältävien, rasvahappojen osuus maitorasvasta on pieni ja johtuu pitkälti rehun rasvahappokoostumuksesta. Rasvahapot ovat joko tyydyttyneitä, kertatyydyttymättömiä tai monityydyttymättömiä. Tyydyttyneistä rasvahapoista maidossa on eniten palmitiinihappoa (C16:0). Monityydyttymättömiä rasvahappoja on maidossa vähän, vain pari prosenttia. Maitorasva sisältää myös jonkin verran tyydyttymättömiä trans-rasvahappoja, joita muodostuu maitorasvaan pötsin mikrobitoiminnan tuloksena.

Maitorasvan rasvahappokoostumusta voidaan muuttaa varsin tehokkaasti lehmien ruokintaa muuttamalla. Lisättäessä rehuun runsaasti monityydyttymättömiä rasvahappoja, esimerkiksi kasviöljynä tai öljykasvinsiemeninä, maitorasvan koostumus muuttuu ravitsemuksellisesti suotuisampaan suuntaan. Tällöin lyhytketjuisten, tyydyttyneiden rasvahappojen osuus maidossa vähenee ja pitkäketjuisten, kerta- ja monityydyttymättömien rasvahappojen osuus lisääntyy (Chilliard ym. 2000; 2001; Chilliard ja Ferlay, 2004; Givens ja Shingfield, 2006). Pötsin rasva-aineenvaihdunnan takia trans-rasvahappojen muodostumista ja rikastumista maitoon ei voida kuitenkaan kokonaan välttää (Harfoot ja Hazlewood, 1988).

Rypsiöljyn lisääminen lypsylehmien rehuun on hyvä menetelmä muuttaa maitorasvan koostumusta ravitsemuksellisesti suotuisampaan suuntaan. Öljyn monityydyttymättömät rasvahapot ovat kuitenkin alttiita pötsimikrobien pelkistysreaktiolle (ts. biohydrogenaatio), jolloin erilaisten reaktiovälituotteiden, kuten trans-rasvahappojen, muodostus pötsissä lisääntyy. Lisättäessä rehuun kokonaisia öljykasvinsiemeniä siemenien tiedetään suojaavan monityydyttymättömiä rasvahappoja pötsimikrobien toiminnalta. Tämän tutkimuksen tavoitteena oli selvittää kuinka hyvin rypsinsiemenen kuori suojaa rypsin monityydyttymättömiä rasvahappoja pelkistykseltä pötsissä ja kuinka paljon tämä vaikuttaa trans-rasvahappojen muodostumiseen biohydrogenaation välituotteena, ja mikä on näiden tekijöiden vaikutus maidon rasvahappokoostumukseen.

\section{Aineisto ja menetelmät}

Kokeessa selvitettiin erilaisten rypsirehujen vaikutusta maidon rasvahappokoostumukseen. Koe toteutettiin 4 x 4 latinalaisen neliön koemallin mukaan Jokioisilla MTT Kotieläintuotannon Koeeläintallilla keväällä 2006. Kokeessa käytettiin neljää pötsifistelöityä lypsylehmää. Koejakson pituus oli 21 päivää. Kokeen aikana lehmät söivät vapaasti seosrehua, jonka karkearehun ja väkirehun suhde oli 60:40. Karkearehuna käytettiin rajoittuneesti käynyttä säilörehua. Koekäsittelystä riippuen lehmien rehuseokseen (kontrolli, ei rasvalisää; C) sekoitettiin rypsiöljyä (RO), kokonaisia rypsinsiemeniä (WR) tai murskattuja rypsinsiemeniä (MR) siten, että rehuseokset sisälsivät rasvaa noin $50 \mathrm{~g} / \mathrm{kg} \mathrm{KA}$. Seosrehut sekoitettiin päivittäin rasvan hapettumisen estämiseksi. Rypsirouhetta annosteltiin rehuseoksiin siten, että raakavalkuaisen saanti oli yhtä suuri kaikilla koekäsittelyillä. Totutusjaksolla lehmät söivät kontrollirehuseosta.

Seosrehut jaettiin lehmille neljä kertaa päivässä. Lehmien syönnit ja maitotuotokset mitattiin päivittäin koko kokeen ajan. Suhteelliset maitonäytteet maidon valkuais-, rasva- ja laktoosipitoisuuden sekä rasvahappokoostumuksen määrittämiseksi otettiin jokaisen jakson viimeisellä viikolla neljältä peräkkäiseltä lypsykerralta. Maidon rasvahappomääritystä varten otetut näytteet pakastettiin välittömästi näytteenoton jälkeen.

Rehunäytteet analysoitiin MTT Kotieläintuotannon tutkimuksen laboratoriossa standardimenetelmin. Rasvan uutto, triglyseridien transmetylaatio ja vapaiden rasvahappojen metylaatio rasvahapon metyyliestereiksi (FAME) rehuista, rypsiöljystä ja maidosta tehtiin Shingfieldin ym. (2003) mukaan. Rasvahapon metyyliesterit (kokonaisrasvahapot ja C18:1-isomeerit) määritettiin kaasukromatografilla, jossa oli liekki-ionisaatiodetektori (FID). Rasvahappojen erottelu toteutettiin CP-Sil 88 kapillaarikolonnilla, jossa käytettiin vetyä kantajakaasuna (Shingfield ym. 2003). Rasvahapot tunnistettiin pääasiassa vertaamalla niiden retentioaikoja metyloitujen rasvahappojen standardeihin (UC-59-M, GLC-68A, GLC-463, Nu-Chek-Prep Inc. ja CRM 164 maitorasvan referenssistandardi, Community Bureau of Reference, Brysseli, Belgia).

Konjugoidun linolihapon (eng conjugated linoleic acid; CLA) isomeerit määritettiin nestegromatografilla, jossa oli neljä peräkkäistä ChromSpher Lipids-kolonnia. Ajoliuoksena käytettiin $0.1 \%$ asetonitriiliä (ACN) heptaanissa $1 \mathrm{ml} / \mathrm{min}$ virtausnopeudella (Shingfield ym. 2003). 
Konjugoidun linolihapon trans,trans-, cis,trans- ja trans,cis-isomeerit tunnistettiin vertaamalla näytteiden kromatogrammeja metyloitujen CLA-isomeeristandardien kromatogrammeihin (Matreya Incorporated, Sigma O-5632) sekä kirjallisuudessa (Sehat ym. 1998, Fritsche ym. 2001) julkaistuihin CLA-kromatogrammeihin. Maidon rasvapitoisuus, valkuaispitoisuus ja laktoosipitoisuus määritettiin infrapuna-analysaattorilla. Tulokset analysoitiin tilastollisesti SAS GLM -proseduurilla mallilla, jossa olivat mukana jakson, lehmän ja ruokinnan vaikutukset.

\section{Tulokset ja tulosten tarkastelu}

Rypsirasvojen lisäys ei vaikuttanut merkitsevästi kokonaiskuiva-aineen eikä muiden ravintoaineiden syöntiin (taulukko 1). Kokonaiskuiva-aineen syönti oli kuitenkin hieman suurempi lisättäessä lehmien rehuun kokonaisia ja murskattuja rypsinsiemeniä kuin ilman rasvalisää tai lisättäessä rehuun rypsiöljyä. Vaikka lehmien päivittäinen rasvan saanti oli noin $1 \mathrm{~kg} /$ päivä rypsirasvaa sisältävillä koekäsittelyillä koko kokeen ajan, koekäsittelyillä ei ollut vaikutusta lehmien maitotuotokseen (28.5, 28.0, 28.3 ja $26.9 \mathrm{~kg} / \mathrm{pv}$ koekäsittelyissä $\mathrm{C}, \mathrm{RO}, \mathrm{WR}$ ja MR vastaavasti, SEM =0.72) eikä valkuais$(31.3,31.0,31.1$ ja $30.5 \mathrm{~g} / \mathrm{kg}, \mathrm{SEM}=0.28)$, rasva- $(41.2,42.2,43.0 \mathrm{ja} 43.0 \mathrm{~g} / \mathrm{kg}$, SEM = 2.09) ja laktoosipitoisuuksiin $(48.9,49.0,49.6$ ja $48.6 \mathrm{~g} / \mathrm{kg}, \mathrm{SEM}=0.59)$. Rasvahappojen kokonaissaannit sekä tyydyttyneiden, kerta- ja monityydyttymättömien rasvahappojen saannit lisääntyivät $(\mathrm{P}<0,001)$ odotetusti rypsirasvoja lisättäessä (taulukko 1).

Rypsirasvojen lisäys muutti maitorasvan koostumusta merkitsevästi. Tyydyttyneiden rasvahappojen osuus maidon kokonaisrasvahapoista väheni $(\mathrm{P}<0,001)$ ja kertatyydyttymättömien rasvahappojen osuus lisääntyi $(\mathrm{P}<0,001)$ rypsirasvoja lisättäessä (taulukko 2). Tyydyttyneiden rasvahappojen osuuden väheneminen johtui erityisesti maitorauhasen de novo-synteesissä muodostuvien lyhytketjuisten $(\leq \mathrm{C} 14)$ rasvahappojen määrän vähentymisestä, mikä on osoitus maitorauhasen rasvahapposynteesin heikkenemisestä lisättäessä suuria annoksia rasvaa märehtijöiden rehuun (Grummer 1991). Myös palmitiinihappopitoisuuden (C16:0) pieneneminen saattaa olla osoitus maitorauhasen de novo-synteesin heikkenemisestä. Rypsiöljyn lisäys vähensi tyydyttyneiden rasvahappojen osuutta (taulukko $2 ; \mathrm{P}<0,001)$ ja lisäsi trans-rasvahappojen osuutta $(\mathrm{P}<0,001)$ merkitsevästi muihin rypsilisiin verrattuna. Lisättäessä rehuun kokonaisia tai murskattuja rypsinsiemeniä, niiden kuoret suojaavat monityydyttymättömiä rasvahappoja pötsissä, jolloin myös biohydrogenaation välituotteena muodostuvien trans-rasvahappojen kertyminen pötsiin on vähäisempää.

Rypsirehujen vaikutus maidon C18:1-isomeereihin ja CLA:n koostumukseen on esitetty taulukoissa 3 ja 4. Öljyhapon (cis-9 C18:1) pitoisuuden lisääntyminen (taulukko 3; $\mathrm{P}<0,001$ ) rypsirehuja lisättäessä selittää lähes yksinomaan kertatyydyttymättömien rasvahappojen kokonaismäärän lisääntymisen maidon kokonaisrasvahapoista. Rypsin suuri öljyhappopitoisuus ei selitä yksin maidon öljyhappopitoisuuden lisääntymistä. Rypsin rasvahappokoostumuksen lisäksi maidon öljyhappopitoisuus riippuu sekä rasvahappojen epätäydellisestä biohydrogenaatiosta pötsissä että maitorauhasen $\Delta^{9}$-desaturaasientsyymin vaikutuksesta (Chilliard ym., 2000). Vaikka rypsirehujen vaikutus maidon C18:2-rasvahappojen pitoisuuteen oli suhteellisen pieni, linolihapon (C18:2n-6; cis9, cis-12 C18:2) osuus väheni merkitsevästi rypsirasvoja lisättäessä (taulukko 4; $\mathrm{P}<0,05$ ). Cis-9, trans11 CLA oli maidon pääasiallisin CLA-isomeeri ja sen pitoisuus oli suurimmillaan lisättäessä rypsiöljyä lehmien rehuun $(\mathrm{P}<0,001)$. Myös trans-7, cis-9 CLA:n osuus maidon CLA:sta lisääntyi rypsirasvoja lisättäessä ja sen osuus oli suurimmillaan rypsiöljyä lisättäessä $(\mathrm{P}<0.01)$. Maidon cis-9 C18:1, cis-9, trans-11- ja trans-7, cis-9 CLA:n pitoisuudet olivat suuria, mikä selittyy pääosin maitorauhasen $\Delta^{9}$-desaturaasientsyymin aktiivisuudesta (Griinari ym. 2000, Corl ym. 2001 ja 2002).

\section{Johtopäätökset}

Lisäämällä rypsin rasvaa lypsylehmien rehuun maidon rasvahappokoostumusta saatiin muutettua ravitsemuksellisesti suotuisampaan suuntaan. Kaikki rasvalisät vähensivät maitorasvan tyydyttyneiden rasvahappojen pitoisuutta ja lisäsivät kerta- ja monityydyttymättömien rasvahappojen osuutta kontrolliruokintaan verrattuna. Trans-rasvahappojen rikastumista maitoon ei kuitenkaan voitu kokonaan välttää pötsimikrobien rasva-aineenvaihdunnan takia. Trans-rasvahappojen rikastuminen maitoon oli suurimmillaan lisättäessä rypsiöljyä lehmien rehuun. Vaikka kaikki rasvalisät vähensivät maitorasvan tyydyttyneiden rasvahappojen pitoisuutta ja lisäsivät kerta- ja monityydyttymättömien 
rasvahappojen osuutta kontrolliruokintaan verrattuna, ravitsemuksellisesti paras muutos maidon rasvahappokoostumukseen saatiin lisättäessä lehmien rehuun murskattuja rypsinsiemeniä.

\section{Kirjallisuus}

Corl B.A., Baumgard L.H., Dwyer D.A., Griinari J.M., Phillips B.S. \& Bauman D.E. 2001. The role of delta(9)-desaturase in the production of cis-9, trans-11 CLA. Journal of Nutritional Biochemistry 12: 622-630.

Corl B.A., Baumgard L.H., Griinari J.M., Delmonte, P., Morehouse K.M., Yurawecz M.P. \& Bauman D.E. 2002. Trans-9, cis-9 CLA is synthesized endogenously by delta(9)-desaturase in dairy cows. Lipids 37 : 681-688.

Chilliard Y, Ferlay A \& Doreau M. 2001. Effect of different types of forages, animal fat or marine oils in cow's diet on milk fat secretion and composition, especially conjugated linoleic acid (CLA) and polyunsaturated fatty acids. Livestock Production Science 70: 31-48.

Chilliard Y \& Ferlay A. 2004. Dietary lipids and forages interactions on cow and goat milk fatty acid composition and sensory properties. Reproduction Nutrition Development 44: 467-492.

Chillard Y, Ferlay A, Mansbridge R.M \& Doreau M. 2000. Ruminant milk fat plasticity: nutritional control of saturated, polyunsaturated, trans and conjugated fatty acids. Ann. Zootech. 49: 181-205.

Fritsche, J., Yurawecz, M.P., Pawlosky, R., Flanagan, V.P., Steinhart, H. \& Ku, Y. 2001. Spectroscopic characterization of unusual conjugated linoleic acid (CLA) isomers. Journal of Separation Science 24: 559-618.

Givens D.I. \& Shingfield K.J.. 2006. Optimising dairy milk fatty acid composition. In: Improving the fat content of foods (Ed. C M Williams and J Buttriss), Woodhead Publishing Ltd., Cambridge, UK, pp. 252-280.

Griinari J.M., Corl, B.A., Lacy, S.H., Chouinard, P.Y., Nurmela K.V.V. \& Bauman, D.E. 2000. Conjugated linoleic acid is synthesized endogenously in lactating dairy cows by $\Delta^{9}$ - desaturase. Journal of Nutrition 130 : 2285-2291.

Grummer, R.R. \& Carrol D.J. 1991. Effects of dietary fat on metabolic disorders and reproductive performance of dairy cattle. Journal of Animal Science 69: 3838-3852.

Harfoot C.G. \& Hazelwood G.P. 1988. Lipid Metabolism in the Rumen. In: The Rumen Microbial Ecosystem (Ed. PN Hobson), Elsevier Science, London, UK, pp. 285-322.

Sehat, N., Yurawecz, M.P., Roach, J.A.G., Mossoba, M.M., Kramer, J.K.G. \& Ku, Y. 1998.

Silver-ion high-performance liquid chromatographic separation and identification of conjugated linoleic acid isomers. Lipids 33: 217-221.

Shingfield, K.J., Ahvenjärvi, S., Toivonen, V., Ärölä, A., Nurmela, K.V.V., Huhtanen, P. \& Griinari J.M. 2003. Effect of dietary fish oil on biohydrogenation of fatty acids and milk fatty acid content in cows. Animal Science 77: 165-179. 
Taulukko 1. Rypsirasvalisien vaikutus ravintoaineiden ja rasvahappojen saantiin.

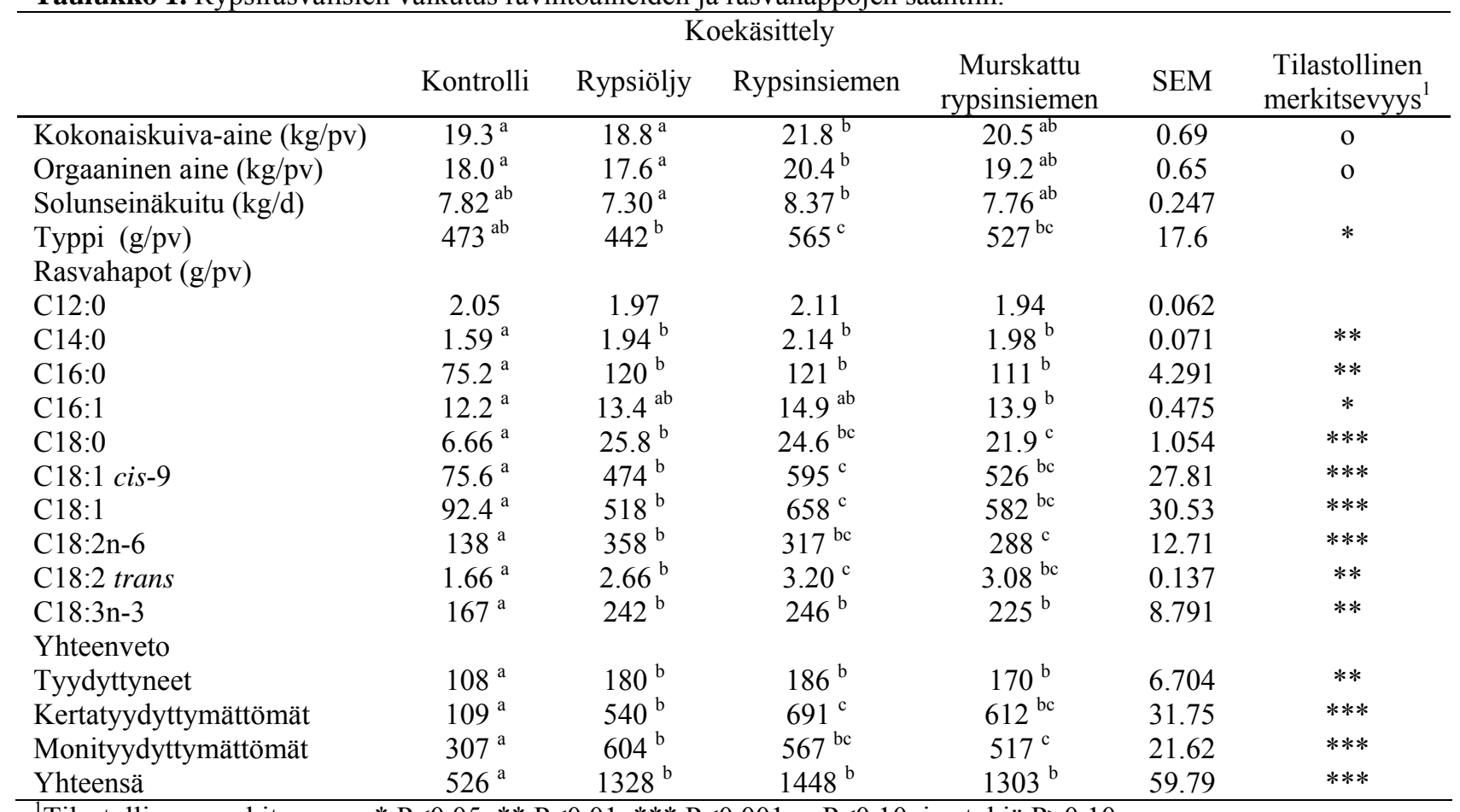

${ }^{1}$ Tilastollinen merkitsevyys: * $\mathrm{P}<0,05, * * \mathrm{P}<0,01, * * * \mathrm{P}<0,001$, o $\mathrm{P}<0,10$, jos tyhjä $\mathrm{P}>0,10$.

Taulukko 2. Rypsirasvalisien vaikutus maidon rasvahappokoostumukseen (g/100g rasvahappoja).

\begin{tabular}{|c|c|c|c|c|c|c|}
\hline & \multicolumn{4}{|c|}{ Koekäsittely } & \multirow[b]{2}{*}{ SEM } & \multirow[b]{2}{*}{$\begin{array}{r}\text { Tilastollinen } \\
\text { merkitsevyys }\end{array}$} \\
\hline & Kontrolli & Rypsiöljy & Rypsinsiemen & $\begin{array}{l}\text { Murskattu } \\
\text { rypsinsiemen }\end{array}$ & & \\
\hline $\mathrm{C} 4: 0$ & $5.09^{\mathrm{a}}$ & $4.59^{b}$ & $5.25^{\mathrm{a}}$ & $4.88^{\mathrm{ab}}$ & 0.112 & $*$ \\
\hline C6:0 & $2.56^{\mathrm{a}}$ & $1.89^{b}$ & $2.32^{c}$ & $2.07^{\mathrm{b}}$ & 0.068 & $* *$ \\
\hline C8:0 & $1.35^{\mathrm{a}}$ & $0.87^{b}$ & $1.12^{\mathrm{c}}$ & $0.96^{b c}$ & 0.047 & $* *$ \\
\hline C10:0 & $2.64^{\mathrm{a}}$ & $1.51^{\mathrm{b}}$ & $1.95^{\mathrm{c}}$ & $1.69^{b c}$ & 0.103 & $* *$ \\
\hline $\mathrm{C} 12: 0$ & $3.01^{\mathrm{a}}$ & $1.71^{\mathrm{b}}$ & $2.16^{\mathrm{c}}$ & $1.87^{\mathrm{bc}}$ & 0.102 & $* * *$ \\
\hline C14:0 & $11.0^{\mathrm{a}}$ & $7.12^{b}$ & $8.85^{c}$ & $7.84^{b}$ & 0.212 & $* * *$ \\
\hline C16:0 & $31.4^{\mathrm{a}}$ & $18.6^{b}$ & $24.0^{\mathrm{c}}$ & $20.4^{b}$ & 0.797 & $* * *$ \\
\hline C16:1 & $1.88^{\mathrm{a}}$ & $1.58^{\mathrm{b}}$ & $1.53^{b}$ & $1.51^{\mathrm{b}}$ & 0.026 & $* * *$ \\
\hline C18:0 & $9.91^{\mathrm{a}}$ & $17.8^{b}$ & $15.5^{c}$ & $17.3^{b}$ & 0.481 & $* * *$ \\
\hline C18:1 cis yht. & $19.2^{\mathrm{a}}$ & $31.2^{b}$ & $26.3^{c}$ & $30.3^{b}$ & 0.925 & $* * *$ \\
\hline C18:1 trans yht. & $2.25^{\mathrm{a}}$ & $4.95^{b}$ & $2.98^{\mathrm{ac}}$ & $3.42^{c}$ & 0.275 & $* *$ \\
\hline C18:1 yht. & $21.5^{\mathrm{a}}$ & $36.2^{b}$ & $29.3^{c}$ & $33.7^{b}$ & 0.814 & $* * *$ \\
\hline C18:2 yht. $^{2}$ & $1.71^{\mathrm{ab}}$ & $1.75^{b}$ & $1.58^{\mathrm{ab}}$ & $1.53^{\mathrm{b}}$ & 0.055 & o \\
\hline $\mathrm{CLA}^{3}$ & $0.47^{\mathrm{a}}$ & $0.76^{\mathrm{b}}$ & $0.41^{\mathrm{c}}$ & $0.47^{\mathrm{a}}$ & 0.019 & $* * *$ \\
\hline C18:3n-3 & $0.44^{\mathrm{a}}$ & $0.28^{b}$ & $0.39^{c}$ & $0.32^{\mathrm{d}}$ & 0.008 & $* * *$ \\
\hline \multicolumn{7}{|l|}{ Yhteenveto } \\
\hline Tyydyttyneet & $72.1^{\mathrm{a}}$ & $58.1^{\mathrm{b}}$ & $65.3^{c}$ & $61.1^{\mathrm{d}}$ & 0.842 & $* * *$ \\
\hline Kertatyydyttymättömät & $26.4^{\mathrm{a}}$ & $39.9^{b}$ & $33.2^{\mathrm{c}}$ & $37.4^{\mathrm{b}}$ & 0.815 & $* * *$ \\
\hline Trans-rasvahapot & $3.91^{\mathrm{a}}$ & $7.12^{b}$ & $4.51^{\mathrm{ac}}$ & $5.08^{c}$ & 0.331 & $* *$ \\
\hline Monityydyttymättömät yht. & $3.05^{\mathrm{a}}$ & $3.10^{\mathrm{a}}$ & $2.72^{\mathrm{b}}$ & $2.64^{\mathrm{b}}$ & 0.071 & $*$ \\
\hline
\end{tabular}


Taulukko 3. Rypsirasvalisien vaikutus maidon C18:1-rasvahappokoostumukseen (g/100g rasvahappoja).

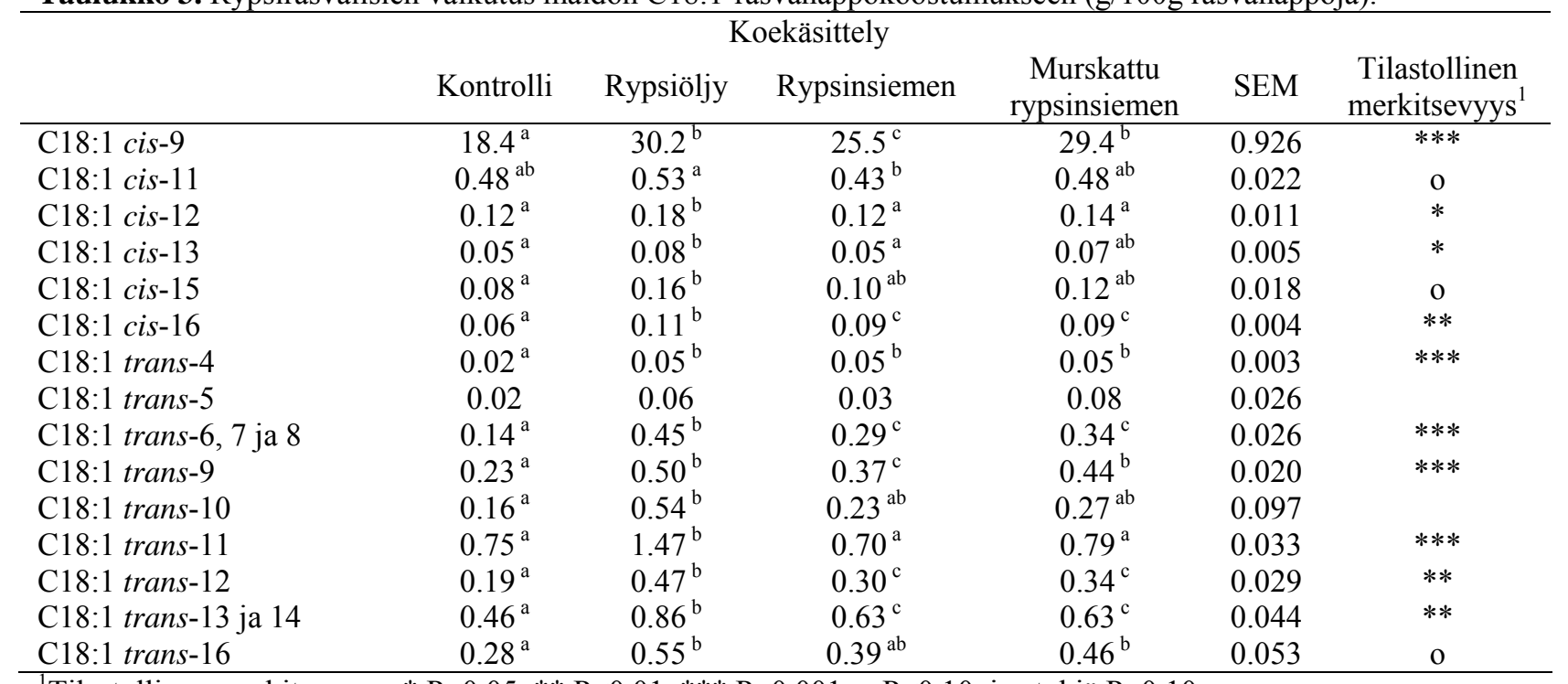

${ }^{1}$ Tilastollinen merkitsevyys: * $\mathrm{P}<0,05, * * \mathrm{P}<0,01, * * * \mathrm{P}<0,001$, o $\mathrm{P}<0,10$, jos tyhjä $\mathrm{P}>0,10$.

Taulukko 4. Rypsirasvalisien vaikutus maidon CLA- ja C18:2-rasvahappokoostumukseen (g/100g rasvahappoja).

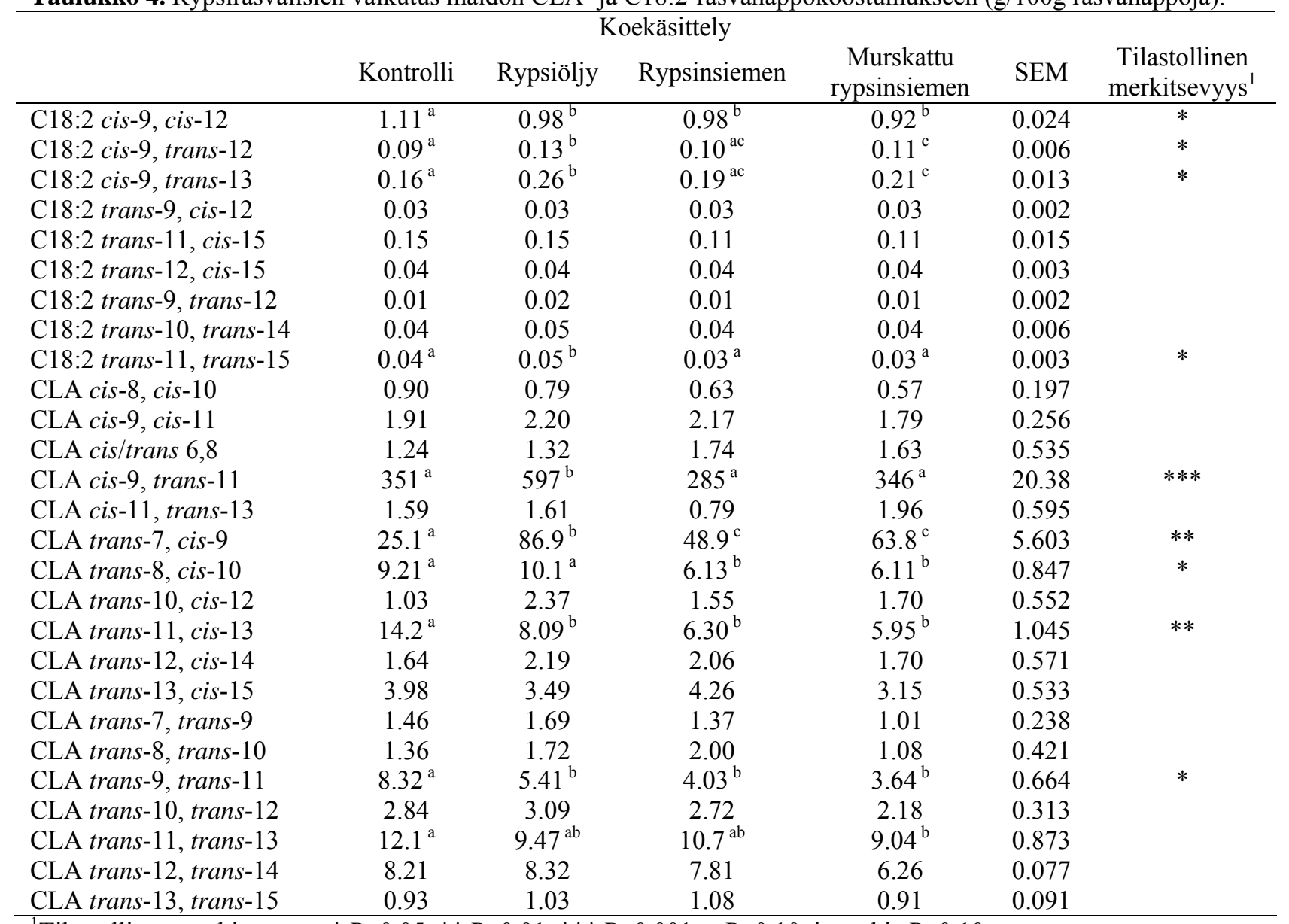

${ }^{\mathrm{I}}$ Tilastollinen merkitsevyys: * $\mathrm{P}<0,05, * * \mathrm{P}<0,01, * * * \mathrm{P}<0,001$, o $\mathrm{P}<0,10$, jos tyhjä $\mathrm{P}>0,10$. 